\title{
Artes, medios y tecnologías. Una introducción al análisis de prácticas híbridas locales
}

Arts, media and technologies. An introduction to the analysis of local hybrid practices

Natalia Matewecki nmatewecki@gmail.com

http://orcid.org/0000-0002-7659-279X

Instituto de Historia del Arte Argentino y Americano; Facultad de Bellas Artes;

Universidad Nacional de La Plata (Argentina)

María de las Mercedes Reitano reitanomariam@yahoo.com

Instituto de Historia del Arte Argentino y Americano; Facultad de Bellas Artes;

Universidad Nacional de La Plata (Argentina)

\section{Resumen}

En este artículo se describe el estado de avance del proyecto de Investigación + Desarrollo (I+D) denominado "Artes, Medios y Tecnologías. Estudio de prácticas híbridas locales para la producción de nuevas teorías, conceptos y categorías". La investigación pretende reunir una serie de casos de hibridación entre artes, medios y tecnologías con el fin de construir 
conceptos y categorías que surjan del análisis comparativo de los casos seleccionados. De la interacción de las artes, los medios, las ciencias y las nuevas tecnologías se configuran problemáticas en torno a las imágenes híbridas: imágenes técnicas científicas apropiadas por el arte, imágenes artísticas o científicas producidas por medios tecnológicos, imágenes artísticas producidas por medios tradicionales que aplican métodos o exploran temáticas de las ciencias e imágenes donde convergen lo culto, lo masivo y lo popular. El estudio de casos locales conformado por artistas y colectivos que trabajan sobre estas intersecciones, serán abordados desde una perspectiva interdisciplinar que incluye enfoques y aportes provenientes de los estudios visuales, la historia del arte, la semiótica, la filosofía, las ciencias biológicas, las ciencias físicas y las ciencias informáticas.

Palabras clave: artes; medios; tecnologías; hibridación; convergencia.

\section{Abstract}

This essay describes the state of progress of the $R+D$ project called "Arts, Media and Technologies. Study of local hybrid practices for the production of new theories, concepts and categories". The research aims to gather a series of cases of hybridization amongst arts, media and technologies in order to build concepts and categories that arise from the comparative analysis of selected cases. The interaction of the arts, media, sciences and new technologies are problematic around hybrid images: scientific technical images appropriated by art, artistic or scientific images produced by technological means, artistic images produced by traditional means that they apply methods or explore themes of sciences and images where the cult, the mass and the popular converge. The study of local cases conformed by artists and collectives that work on these intersections, will be approached from an interdisciplinary perspective that includes approaches and contributions from visual studies, art history, semiotics, philosophy, biological sciences, sciences physics and computer science.

Keywords: arts; media; technologies; hybridization; convergence.

Con este proyecto se propone constituir un aporte sustancial al avance del conocimiento de un conjunto de prácticas locales que vinculan las artes, los medios y las tecnologías, a partir de la producción de un marco teórico propio, así como de conceptos y categorías particulares que 
surjan del análisis de los casos. Se seleccionarán y analizarán producciones híbridas, géneros mixtos y nuevos géneros derivados de las relaciones entre artes, medios, ciencias y tecnologías, que serán abordados con un enfoque interdisciplinario, como el que se plantea desde la cátedra de Historia de los Medios y Sistemas de Comunicación Contemporáneos de la Facultad de Bellas Artes, de la Universidad Nacional de La Plata (UNLP).

En este sentido, se pretende generar conceptualizaciones que ayuden a la construcción de un marco epistemológico necesario para el abordaje de obras nacionales que se encuentran en un lugar intermedio, de convergencias y mixturas, entre lo local y lo global; lo natural y lo cultural; lo culto, lo masivo y lo popular.

\section{Marco teórico}

El enfoque interdisciplinario que se propone para el desarrollo de este proyecto de investigación, coincide con la convergencia actual que se da entre las artes, los medios y las tecnologías de la información y la comunicación. Este tipo de enfoque se enmarca dentro de los Estudios Visuales, un campo de estudio cuya lógica no adhiere a una única disciplina, sino que propone distintos marcos, métodos y enfoques para analizar las imágenes. El cambio propuesto por los Estudios Visuales desde lo disciplinar hacia lo interdisciplinar se dio en simultáneo con los cambios producidos dentro del ámbito de las prácticas artísticas: el pasaje del arte moderno al arte posmoderno. El resultado de estos cambios -en el arte y en la academia- supuso una transformación en la manera de entender el lugar del arte en la cultura del siglo XX, de modo tal que dentro de los Estudios Visuales se gestó un área específica conocida como Cultura Visual. El texto de Mirzoeff publicado en 1999, An Introduction to Visual Culture (2003), expone los cambios que se producen a partir del crecimiento, la masificación y la globalización de las imágenes dados a través de los medios masivos y del uso de las nuevas tecnologías de la información y la comunicación. En este sentido, reivindica el estudio de la visualidad como marco para romper con los límites entre lo culto y lo popular consolidados por las disciplinas académicas tradicionales.

En este sentido, Rosi Braidotti, quien adscribe a la corriente del posthumanismo, señala que los tiempos actuales exigen disciplinas humanistas posthumanas. Se debe superar el modelo humanista clásico con el fin de dirigirnos hacia una intensa forma de interdisciplinariedad, transversalidad y vaivenes continuos entre diferentes discursos (Braidotti, 2015). Así, las ciencias posthumanas se caracterizan por una nueva alianza entre las artes, los medios, las 
tecnologías y las ciencias, que están en condiciones de difundir múltiples redes de conocimientos.

Por lo tanto, los estudios interdisciplinarios y transdisciplinarios son necesarios en la actualidad debido a que los objetos de análisis también constituyen una forma de multiplicidad, de copresencia e hibridación de elementos. Como hace referencia Mieke Bal (2006), hoy en día el concepto de hibridación designa al estado postcolonial, un estado que se define por su indefinición dado por los constantes cruces, mezclas, intersecciones e intercambios entre los distintos elementos que lo componen. La idealización de este estado se basa en la diversidad cultural, en aquello que García Canclini (1989) denomina culturas híbridas en tanto manifiestan las mezclas entre lo culto, lo popular y lo masivo. En la actualidad, casi todas las áreas de la cultura están atravesadas por algún tipo de hibridación, desde la política y la economía hasta la ecología, los medios, la tecnología o el arte, presentan algún tipo de mixtura. Se puede considerar que las producciones de nuestra cultura no son puras, están plagadas de préstamos, apropiaciones, alusiones, citas y comentarios; es una cultura del pastiche y del bricolaje que mezcla, combina y fusiona elementos provenientes de distintos orígenes. Así se presenta y se celebra el concepto hibridación en la contemporaneidad como copresencia de elementos diversos que vuelven borrosa cualquier división.

En el campo del arte y los medios, Manovich (2006) considera que las nuevas tecnologías basadas en el código numérico son las responsables de la revolución del híbrido. La informática vuelve virtual a las cosas sacándolas de su medio físico de origen para transformarlas en algoritmos, una vez ocurrido esto, es posible manipular, modificar y combinar los elementos a gusto generando un remix permanente. Lo que se remixa no es sólo el contenido de los distintos medios sino sus técnicas, métodos de trabajos, formas de representación y expresión, esto es lo que Manovich (2007) considera un remix profundo, la esencia de la revolución del híbrido. Es decir, la conversión de medios puros (fotografía, cinematografía, animación, gráfica 3D) en medios híbridos o metamedium: medios que usan una o todas las técnicas que antes pertenecían exclusivamente a cada uno de los medios puros.

Lo interesante de los medios hoy, señalan autores como Machado (2006) y Bellour (2009), no está puesto en la individualidad y delimitación de cada uno (en su forma de actuar separada e independientemente de los otros) sino por el contrario en las conexiones, intersecciones y convergencias que existen entre medios "lo que hay de un medio en otro: qué hay de pintura en el cine, de cine en la literatura, de fotografía en la música, de televisión en el video" (Machado, 2006: s/p). Las fronteras entre soportes, medios y lenguajes se disfuman generando 
así producciones híbridas, mestizas, compuestas de fuentes diversas, en donde los nuevos medios conviven con los viejos medios en una suerte de convergencia medial.

\section{Análisis de casos. Primeras categorías y conceptos desarrollados}

El corpus de la investigación está conformado por ejemplos de activismo artístico, arte sonoro, artes visuales y artes mediales que manifiestan un carácter híbrido y convergente. El análisis propuesto contribuye al desarrollo de categorías y conceptualizaciones teóricas propias, generadas a partir del estudio de los siguientes casos:

1. Las acciones en el espacio público de los pañuelos blancos, y más recientemente, de los pañuelos verdes, son denominadas pañuelazos. Son acciones masivas, performáticas, al estilo flashmob, que están pensadas para la transmisión en vivo y directo a través de medios tradicionales como la televisión, así como también, mediante internet y redes sociales que promueven el fenómeno de viralización de la información.

En consecuencia, la circulación de estas acciones que evidencian los cruces entre lo artístico, lo mediático y lo popular, adoptan en la actualidad dos vías por las que el contenido converge y fluye del espacio físico urbano de la calle al espacio virtual de las redes sociales.

Por tales características, se tendrán en cuenta algunas nociones referidas a la cultura de la convergencia, la cultura participativa, la inteligencia colectiva y el ciberactivismo artístico, para el desarrollo de conceptualizaciones propias y locales.

2. El análisis de la música y el arte sonoro se realiza teniendo en cuenta como marco los Estudios Visuales y Culturales. Se toma la propuesta de artistas como Tonolec, Mariana Baraj, Campo, Lisandro Aristimuño y Mene Savasta Alsina, quienes manifiestan la convergencia de lo culto con lo popular al incorporar en sus obras culturas originarias, culturas populares o sonidos de la naturaleza. En la mayoría de los casos, se propone un continuum naturaleza-cultura (Braidotti, 2015) al mediar los sonidos naturales de manera tecnológica.

Por esta razón, se desarrolla un concepto denominado música tecnoautóctona que refiere a la fusión de la música electroacústica con sonidos tomados de la naturaleza (cantos de pájaros, viento, agua, etc.); sonidos producidos por culturas originarias (recitado, voceo y cantos en lenguas originarias); o sonidos producidos por la cultura urbana (ruidos y diálogos en la calle, en medios de transporte, etcétera).

3. Para abordar la relación arte, ciencia y tecnología, se toma como antecedente a los artistas de la Bauhaus, quienes trabajan microfotografía y macrofotografía, con el fin de establecer 
vínculos con artistas argentinos contemporáneos como Mauro Machado, Gustavo Romano y Luciana Paoletti. En la producción de estos artistas se aprecia el uso de microscopios o drones que generan una imagen en la que el espacio es abordado de manera micro o macro.

En este sentido, se propone el concepto de encuadre planificado, por cuanto las consecuencias del encuadre manifiestan características formales específicas, sin tener en cuenta el arriba y el abajo, ni tampoco las cuestiones de escalas. En las imágenes tomadas por microscopios o en las imágenes aéreas, se suprime el centro de referencia (horizonte) que da como resultado, en general, una imagen abstracta, bidimensional y plana.

El concepto de encuadre planificado está planteado en un doble sentido, por una parte, el encuadre es pensado o planeado por el artista, y por otra parte, la imagen captada resulta plana, chata, sin profundidad. El desarrollo de este concepto es fundamental dentro de las configuraciones espaciales de las prácticas artísticas contemporáneas, especialmente, si pensamos en el acceso a imágenes territoriales satelitales, en el footage producido por drones o en la proliferación de artefactos de captura ópticos que permiten amplificar casi cualquier objeto y subvertir su uso científico.

4. El concepto de hibridación designa el encuentro de orígenes y naturalezas dispares reunidas de manera tal que sus diferencias se intersectan en algún punto; y es allí, en esa zona fronteriza en donde se ubica tanto el conflicto como la conciliación. Por eso, la hibridación no deja de ser un aspecto tensionante dentro de la cultura contemporánea, ya sea promoviendo la unión o generando fricciones, las producciones mixtas oscilan entre lo único, dado por la suma de las partes que generan algo totalmente nuevo, y lo múltiple, provocado por el apilamiento y la superposición visible de cada uno de sus elementos de origen.

Teniendo cuenta una serie de producciones de bioarte, un género artístico considerado híbrido por su carácter interdisciplinario y por combinar bits, átomos y genes, se plantea establecer una clasificación de los modos en que la hibridación se manifiesta, ya sea como integración, conflicto, yuxtaposición, fusión, multiplicidad o unicidad.

Los casos analizados corresponden a producciones de bioartistas locales, entre ellos: Darío Sacco, Luciana Paoletti, Daniel Alvarez Olmedo, Marina Zerbarini, Joaquín Fargas y los colectivos Proyecto Untitled y Ala Plástica.

\section{A modo de cierre}


Con este proyecto pretendemos generar nociones, conceptos y categorías novedosas y particulares sobre el tema de la convergencia entre artes, medios y tecnologías. El fin de esta investigación es contribuir al avance del conocimiento teniendo en cuenta el desarrollo de marcos teóricos específicos y propios, dados a partir del análisis de casos locales.

Proponemos hacerlo a través de un enfoque interdisciplinario que se adecúe a las nuevas estructuras del pensamiento y el conocimiento caracterizadas por la mediación tecnológica, la hibridación de lenguajes y el cruce disciplinario.

Los resultados de la investigación contribuyen no solo al avance en el campo de los estudios visuales y de la cultura visual en general, sino también a la transferencia de conocimiento en el ámbito particular de la cátedra de Historia de los Medios y Sistemas de Comunicación Contemporáneos.

\section{Bibliografía}

Bal, M. (2006). Conceptos viajeros en las humanidades. Estudios Visuales, 3, pp. 27-77.

Bellour, R. (2009). Entre Imágenes. Foto. Cine. Video. Buenos Aires: Colihue.

Braidotti, R. (2015). Lo Posthumano. Barcelona: Gedisa.

García Canclini, N. (1989). Culturas Híbridas, Estrategias para entrar y salir de la Modernidad. México: Grijalbo.

Machado, A. (2006). Convergencia y divergencia de Medios. Miradas, EICTV, La Habana.

Manovich, L. (2006). ¿Qué son los nuevos medios? En El lenguaje de los nuevos medios (pp.63109). Barcelona: Paidós.

Manovich, L. (2007). Understanding Hybrid Media. En Hertz, B. S. (Ed.). Animated Painting (pp. 36-47). San Diego: San Diego Museum of Art.

Mirzoeff, N. (2003). Una introducción a la Cultura Visual. Buenos Aires: Paidós. 